\title{
Transducerless Position and Velocity Estimation in Induction and Salient AC Machines
}

\author{
Patrick L. Jansen, Member, IEEE, and Robert D. Lorenz, Senior Member, IEEE
}

\begin{abstract}
This paper presents a viable transducerless rotor position and velocity estimation scheme for PWM inverter driven induction, synchronous, and reluctance machines with the capability of providing robust and accurate dynamic estimation independent of operating point, including zero and very high speeds, light and heavy loading. The injection of a balanced three-phase high frequency signal $(500$ to $2 \mathrm{kHz})$ generated by the inverter, followed by appropriate signal demodulation and processing combined with a closed-loop observer, enable the tracking of rotor magnetic saliencies from the machine terminals. Although rotor magnetic saliency is inherent within reluctance machines, and most synchronous machines, saliency in the induction machine is introduced via a modulation of the rotor slot leakage with minimal detrimental effects on the machine performance. Experimental verification for the induction machine is included.
\end{abstract}

\begin{tabular}{|c|c|}
\hline \multicolumn{2}{|r|}{ NOMENCLATURE } \\
\hline *, & $\begin{array}{l}\text { Denotes estimated and commanded quantities, } \\
\text { respectively. }\end{array}$ \\
\hline$r, s$ & $\begin{array}{l}\text { Superscripts denoting rotor and stator reference } \\
\text { frames. }\end{array}$ \\
\hline$b$ & Net viscous damping. \\
\hline BPF, LPF & Band, low pass filter. \\
\hline $\boldsymbol{i}_{q d s}, \boldsymbol{\nu}_{q d s}$ & $\begin{array}{l}\text { Net stator current and voltage vectors; i.e., } \\
\boldsymbol{i}_{q d s}=\left[i_{q s}, i_{d s}\right]\end{array}$ \\
\hline $\boldsymbol{i}_{q d s i}, \nu_{q d s i}$ & $\begin{array}{l}\text { Signal component stator current and voltage } \\
\text { vectors. }\end{array}$ \\
\hline $\boldsymbol{i}_{q d s 1}, \nu_{q d s 1}$ & $\begin{array}{l}\text { Fundamental component stator current and } \\
\text { voltage vectors. }\end{array}$ \\
\hline$J$ & Net rotor + load inertia. \\
\hline$K_{1}, K_{2}, K_{3}$ & Linear controller gains of observer. \\
\hline$L_{l r}, L_{l s}$ & Rotor, stator leakage inductance. \\
\hline$p$ & Derivative operator. \\
\hline$\tilde{Z}_{s}$ & $\begin{array}{l}\text { Steady state impedance seen from the stator } \\
\text { terminals. }\end{array}$ \\
\hline$\lambda_{q d s}^{s}$ & Stator flux linkage vector. \\
\hline$\sigma L_{s}$ & Stator transient inductance. \\
\hline$\tau_{r}$ & Rotor time constant. \\
\hline$\theta_{r}$ & Rotor position. \\
\hline$\omega_{i}$ & Injected signal frequency. \\
\hline$\omega_{r}$ & Rotor velocity. \\
\hline
\end{tabular}

Paper IPCSD 94-82, approved by the Industrial Drives Committee of the IEEE Industry Applications Society for presentation at the 1994 Industry Applications Society Annual Meeting, Denver, CO, October 2-7. This work received financial support by the National Science Foundation (NSF) and the Wisconsin Electric Machines and Power Electronics Consortium (WEMPEC) of the University of Wisconsin-Madison. Manuscript released for publication October 27, 1994.

P. L. Jansen is with MK Rail Corporation, Boise, ID 83706 USA.

R. D. Lorenz is with the Department of Electrical and Computer Engineering, University of Wisconsin, Madison, WI 53706-1572 USA

IEEE Log Number 9408181.

\section{INTRODUCTION}

$\mathbf{T}$ HE elimination of position and velocity transducers in ac drives has long been an attractive prospect. The shaft transducers and the associated signal wiring are a significant source of failure and cost, and add to the overall volume and mass that must be allocated to the motor at the work site. Numerous approaches have been proposed to estimate the rotor position and/or velocity from the machine terminal properties. The most success-although limited-has been with synchronous and reluctance machines since they are considerably less complex than the induction machine and have inherent spatially dependent properties that can be tracked easily. Position and velocity estimation in induction machines, which are by far the most common machine type and thus offer the greatest potential, are complicated due to the machines' symmetric smooth rotor, induced rotor currents, and slip. Previous approaches to motion estimation in induction machines have had serious limitations in one or more of the following ways [1]-[13]:

- zero and low speed operation is not possible,

- position estimation is not possible.

- velocity estimation is parameter sensitive,

- velocity estimation is valid at steady state only,

- estimation is load dependent (e.g., operation at either light or heavy loading only), and/or

- excessive computation/hardware requirements.

Based upon the above shortcomings, two basic requirements to achieving accurate, parameter insensitive, dynamic position and velocity estimation independent of operating point are:

1) trackable spatial modulation fixed relative to the rotor position, e.g., rotor magnetic saliency, and

2) appropriate signal injection present throughout the entire operating range, including zero speed.

This paper presents a new, viable method of transducerless position and velocity estimation in induction machines (and salient ac machines) incorporating these two requirements, thereby overcoming the limitations of the previous approaches. Though this paper focuses on induction machines, the proposed approach is applicable to all ac machines capable of exhibiting a form of rotor magnetic saliency.

\section{HIGH FREQUENCY ROTOR}

SALIENCY IN INDUCTION MACHINES

The steady state per phase equivalent circuit of a symmetrical induction machine can be drawn as shown in Fig. 1(a). 


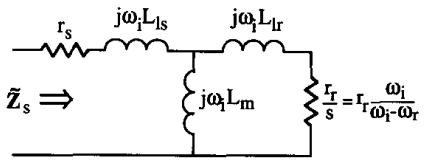

(a)

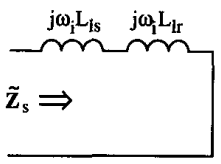

(b)
Fig. 1. (a) Steady state per phase induction machine equivalent circuit. (b) Approximate equivalent circuit for stator current modeling under high frequency signal injection.

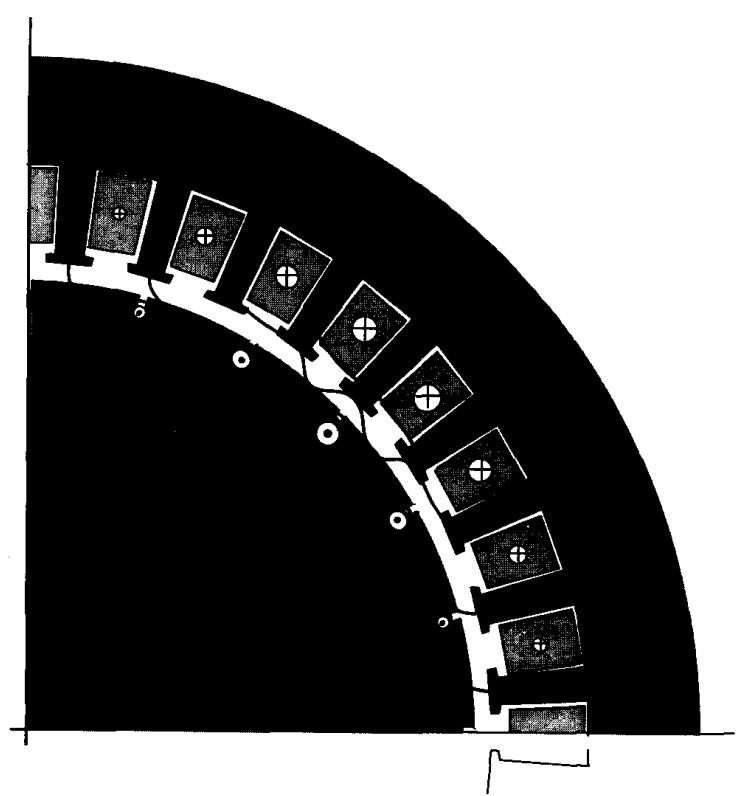

Fig. 2. Illustration of instantaneous currents and flux paths for high-frequency excitation over one pole pitch of a four-pole induction machine.

The impedance seen from the stator terminals is:

$$
\tilde{Z}_{s}=r_{s}+j \omega_{i} \sigma L_{s}+\frac{L_{m}^{2}}{L_{r}} \frac{j \omega_{i}}{1+j \tau_{r}\left(\omega_{i}-\omega_{r}\right)}
$$

where

$$
\sigma L_{s}=L_{l s}+L_{l r}\left(\frac{L_{m}}{L_{m}+L_{l r}}\right) \approx L_{l s}+L_{l r}
$$

For high-excitation frequencies, i.e., $\omega_{i} \gg \omega_{r}$, the stator transient reactance dominates the stator impedance such that

$$
\tilde{Z}_{s} \approx j \omega_{i} \sigma L_{s} .
$$

The high-frequency stator currents are then governed predominately by the stator and rotor leakage reactances as indicated by the approximate circuit in Fig. 1(b). Since the stator and rotor leakage inductances are generally of comparable magnitude in conventional machine designs, a spatial modulation in the rotor leakage inductance should appear as a readily detectable form of magnetic saliency for high-frequency signals. The high-frequency model in Fig. 1(b) implies that nearly all highfrequency air gap flux is confined to the rotor surface as rotor leakage flux as illustrated in Fig. 2 [15]. A spatial modulation

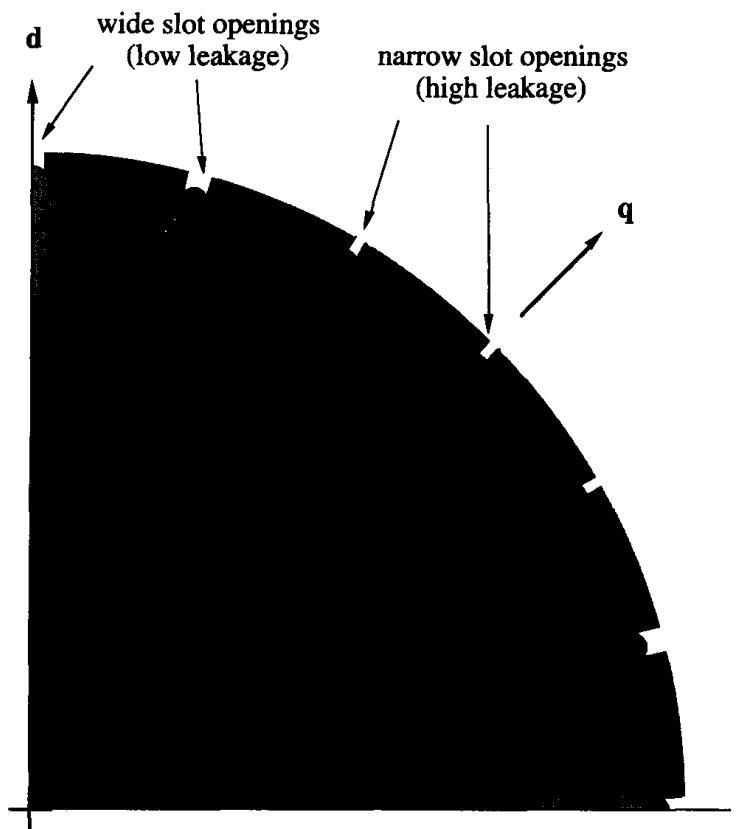

Fig. 3. Rotor of a four-pole squirrel-cage induction motor with spatially variant rotor leakage inductance created via modulation in the width of the slot openings.

of the rotor leakage inductance can therefore be achieved via a periodic variation in the rotor slot opening widths as shown in Fig. 3. The wide slot openings create high-reluctance leakage flux paths, and hence a low inductance, whereas the narrow openings create low-reluctance paths and a high inductance. Completely closed rotor slot bridges are undesirable due to saturation effects which will be discussed in Section V.

Since stator windings are designed to accentuate electromagnetic phenomena spanning one pole pitch, the spatial modulation should also have a period of one pole pitch. This highlights a fundamental problem that has faced many prior approaches that have attempted to track the effects of individual rotor slots, as the stator windings are designed to attenuate, not accentuate, the effects of slotting. With the rotor saliency symmetric about each pole, the absolute rotor position is unique over each pole pitch; i.e., 90 mechanical degrees for a four-pole machine.

A modulation in the rotor leakage should have little detrimental effect on torque or main flux because the rotor impedance is dominated by the rotor resistance, which remains uniform, and not the rotor leakage at the low slip frequencies characteristic of the fundamental excitation. Furthermore, the desired rotor leakage modulation can be designed to exist only at high slip frequencies as proposed in Section V.

\section{TRACKING Rotor SALIENCIES}

This section outlines an approach to tracking saliencies in the rotor leakage inductance via high frequency signal injection. 


\section{A. High Frequency Induction Machine Dynamic Model}

The stator voltage equation in matrix form and the stationary reference frame is

$$
\boldsymbol{\nu}_{q d s}^{s}=r_{s} i_{q d s}^{s}+p \lambda_{q d s}^{s}
$$

where $p$ is the derivative operator. At high frequencies,

$$
\nu_{q d s}^{s} \approx p \lambda_{q d s}^{s}
$$

in which case, based on the above steady state analysis, the stator flux linkage is predominately leakage flux and

$$
\lambda_{q d s}^{s} \approx \sigma \boldsymbol{L}_{s}^{s} \dot{i}_{q d s}^{s} \approx\left(\boldsymbol{L}_{l s}^{s}+\boldsymbol{L}_{l r}^{s}\right) \dot{\boldsymbol{i}}_{q d s}^{s} .
$$

For a symmetrical stator, the stator leakage inductance matrix in the stationary frame is simply

$$
\boldsymbol{L}_{l s}^{s}=\left[\begin{array}{cc}
L_{l s} & 0 \\
0 & L_{l s}
\end{array}\right]
$$

For a rotor containing a spatial modulation in the rotor leakage inductance as depicted in Fig. 3, the rotor leakage inductance matrix can be expressed in the rotor reference frame by position invariant elements as

$$
\boldsymbol{L}_{l r}^{r}=\left[\begin{array}{cc}
L_{l q r} & 0 \\
0 & L_{l d r}
\end{array}\right]
$$

where $L_{l q r} \neq L_{l d r}$. Transforming to the stationary reference frame, cross coupling in addition to position dependent inductances are introduced; i.e.,

$$
\boldsymbol{L}_{l r}^{s}=\left[\begin{array}{cc}
L_{l r}+\Delta L_{l r} \cos 2 \theta_{r} & -\Delta L_{l r} \sin 2 \theta_{r} \\
-\Delta L_{l r} \sin 2 \theta_{r} & L_{l r}-\Delta L_{l r} \cos 2 \theta_{r}
\end{array}\right]
$$

where $\theta_{r}$ is the rotor position in electrical radians and

$$
L_{l r}=\frac{L_{l q r}+L_{l d r}}{2} \quad \Delta L_{l r}=\frac{L_{l q r}-L_{l d r}}{2} .
$$

For an applied balanced polyphase high-frequency signal consisting of

$$
\nu_{q d s i}^{s}=\left[\begin{array}{c}
\nu_{q s i}^{s} \\
v_{d s i}^{s}
\end{array}\right]=V_{s i}\left[\begin{array}{c}
\cos \omega_{i} t \\
-\sin \omega_{i} t
\end{array}\right]
$$

where $\omega_{i} \gg \omega_{r}$, the resulting stator currents can be seen to consist of both position invariant and variant components;

$$
\boldsymbol{i}_{q d s i}^{s}=\left[\begin{array}{c}
i_{q s i}^{s} \\
i_{d s i}^{s}
\end{array}\right] \approx\left[\begin{array}{cc}
I_{i 0} \sin \omega_{i} t+I_{i 1} & \sin \left(2 \theta_{r}-\omega_{i} t\right) \\
I_{i 0} \cos \omega_{i} t+I_{i 1} & \cos \left(2 \theta_{r}-\omega_{i} t\right)
\end{array}\right]
$$

where

and

$$
I_{i 0}=\frac{V_{s i}}{\omega_{i}} \frac{L_{l s}+L_{l r}}{\left(L_{l s}+L_{l r}\right)^{2}-\Delta L_{l r}^{2}}
$$

$$
I_{i 1}=\frac{V_{s i}}{\omega_{i}} \frac{\Delta L_{l r}}{\left(L_{l s}+L_{l r}\right)^{2}-\Delta L_{l r}^{2}}
$$

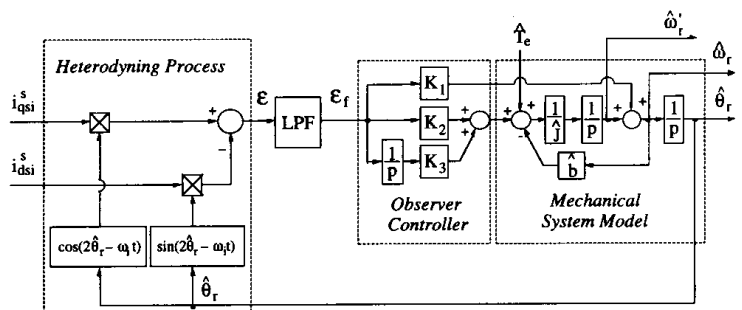

Fig. 4. A closed-loop position and velocity observer incorporating heterodyning to track rotor magnetic saliencies ( $\mathrm{LPF}=$ low pass filter).

\section{B. Signal Demodulation}

A demodulation technique involving heterodyning can be utilized to extract the position information from the stator currents. Multiplication of the currents $i_{q s i}^{s}$ and $i_{d s i}^{s}$ by $\cos \left(2 \hat{\theta}_{r}-\omega_{i} t\right)$ and $\sin \left(2 \hat{\theta}_{r}-\omega_{i} t\right)$, respectively, followed by differencing; i.e.,

$$
\varepsilon=i_{q s i}^{s} \cos \left(2 \hat{\theta}_{r}-\omega_{i} t\right)-i_{d s i}^{s} \sin \left(2 \hat{\theta}_{r}-\omega_{i} t\right)
$$

(where $\hat{\theta}_{r}$ is the estimated rotor position in electrical radians) results in two terms:

$$
\varepsilon=I_{i 0} \sin \left[2\left(\omega_{i} t-\hat{\theta}_{r}\right)\right]+I_{i 1} \sin \left[2\left(\theta_{r}-\hat{\theta}_{r}\right)\right] .
$$

The first term in (15) is at frequency $2\left(\omega_{i}-\hat{\omega}_{r}\right)$ (where $\left.\hat{\theta}_{r}=\int \hat{\omega}_{r} d t\right)$ and contains no useful position information. The second term, however, contains the desirable position information and approaches both dc and zero as $\hat{\theta}_{r} \rightarrow \theta_{r}$. With the selection of signal frequencies such that $\omega_{i} \gg \hat{\omega}_{r}$, the first term can be easily suppressed via low pass filtering. The remaining heterodyned and filtered signal is then in the form of a linear position error; i.e.,

$$
\begin{aligned}
\varepsilon_{f} & \approx I_{i 1} \sin \left[2\left(\theta_{r}-\hat{\theta}_{r}\right)\right] \\
& \approx 2 I_{i 1}\left(\theta_{r}-\hat{\theta}_{r}\right) \rightarrow 0 \text { as } \hat{\theta}_{r} \rightarrow \theta_{r}
\end{aligned}
$$

which can be used as a corrective error input to a Luenberger style position and velocity observer as shown in Fig. 4 [14]. By driving $\varepsilon_{f} \rightarrow 0$, the linear controller in Fig. 4 consisting of gains $K_{1}, K_{2}$, and $K_{3}$ forces convergence of the estimated rotor position on the actual position, i.e., $\hat{\theta}_{r} \rightarrow \theta_{r}$. Both estimated rotor position and velocity are obtained from the observer. Because the velocity estimate, $\hat{\omega}_{r}$, taken after the summation retains the true derivative relationship to $\hat{\theta}_{r}$, it is more accurate than the estimate $\hat{\omega}_{r}^{\prime}$, although noise and highfrequency components that remain in $\varepsilon_{f}$ are directly imparted upon it via the $K_{1}$ gain.

Though not required, an estimate of the electromagnetic torque, $\hat{T}_{e}$, developed by the induction machine is used as feedfoward to drive an estimated mechanical system model to improve the observer estimation dynamic accuracy. In a field oriented system, the commanded torque can also be used. The torque feedfoward reduces phase lag associated with the feedback controller [14].

The closed-loop tracking scheme is similar to that commonly used in resolver-to-digital converters (with the exception of torque feedfoward). It thus shares many of the same attributes. The accuracy of the position and velocity estimates 
are independent of the actual leakage inductance magnitudes. The coefficient $I_{i 1}$ containing the inductance modulation amplitude acts merely as a gain in the closed-loop observer; it does not alter the value to which the observer converges. The closed-loop architecture has low pass filtering attributes that make the estimates highly impervious to noise. Like resolverto-digital converters, the observer can be implemented within a single ASIC.

During operation, the stator current will also contain components at the fundamental excitation frequency and at inverter harmonics. It can be shown that the heterodyning process shifts these components by $\pm\left(2 \hat{\omega}_{r}-\omega_{i}\right)$ in the frequency domain. Thus with sufficient spectral spread these components are also suppressed by the LPF, though some suppression is recommended prior to heterodyning. The additional dynamics of the LPF must, of course, be considered during the design of the observer's controller.

\section{Signal Generation and Frequency Selection}

The selection of the injected signal frequency is primarily dictated by four concerns: conductor and lamination skin effects, spectral spread relative to fundamental excitation, spectral spread relative to inverter harmonics, and the signal generation hardware.

The frequency must be high enough for the skin effect in the rotor bars to force a major portion of the high-frequency flux crossing the air gap to be confined near the rotor surface (as rotor leakage flux) where the modulation occurs, but low enough such that lamination skin effects do not significantly reduce the ratio of rotor to stator leakage. Depending upon the precise rotor bar/slot shape, rotor conductor skin effects can be significant well below $100 \mathrm{~Hz}$, while lamination skin effects can be expected to become significant beyond $400-2 \mathrm{k}$ $\mathrm{Hz}$ depending upon lamination thickness. At $10-20^{+} \mathrm{kHz}$, the lamination skin effects are generally extensive.

The injected signal can be generated via either dedicated circuitry or via the same inverter that is producing the fundamental excitation. The inverter is the preferred generator based upon cost and reliability. Switching frequencies of $10-20^{+}$ $\mathrm{kHz}$ are becoming increasingly common for small- to mediumsize drives. Since the inverter switching harmonics are load dependent and not a balanced polyphase set, they are generally not suitable for the desired signal generation. However, a balanced, polyphase $500-2 \mathrm{k} \mathrm{Hz}$ signal with low harmonic distortion can be synthesized in addition to the fundamental excitation with $5-20^{+} \mathrm{kHz}$ PWM switching. Sufficient spectral spread relative to the fundamental excitation and inverter switching frequencies is thus also achieved. Fig. 5 illustrates such a scheme.

The LPF in Fig. 5 suppresses the high-frequency signal component from the measured currents to minimize interaction with the current regulator. Alternatively, the current command can be augmented to include an estimate of the signal current, thereby achieving decoupling via command feedfoward.

The proposed demodulation scheme assumes the injected signal voltage is a balanced polyphase set of fixed amplitude. Inverter deadtime and bus voltage variations will cause

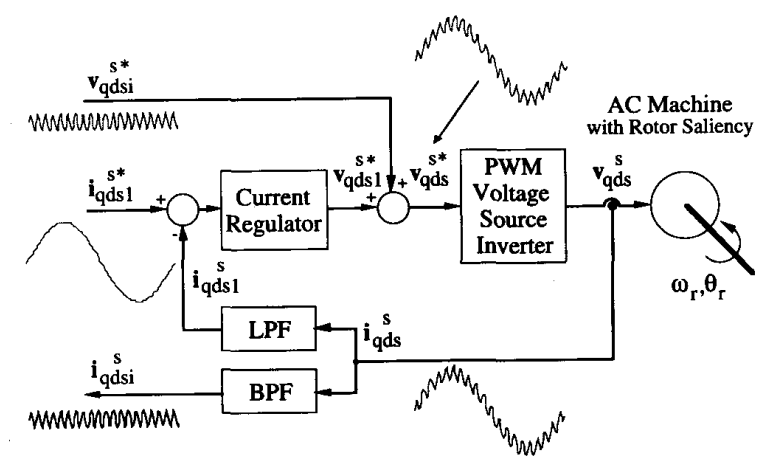

Fig. 5. A high-frequency signal injection scheme utilizing a PWM voltage source inverter to simultaneously synthesize both fundamental and high-frequency components.

undesirable modulation of the signal voltages resulting in estimation errors. The minimization and/or compensation of such effects must be addressed in the system implementation.

Large-drive systems with low-switching frequencies $(300-2 \mathrm{k} \mathrm{Hz})$ are not capable of synthesizing signal voltages of frequencies much beyond $60-400 \mathrm{~Hz}$. With these systems, either external signal generation circuitry is required or the signal injection scheme must be limited to zero and low-speed operation. In the latter case, a back-EMF based closed-loop estimation scheme such as that in [13] could be incorporated to obtain field orientation and velocity estimation over a wide-speed range. With sufficient current regulator bandwidth, the signal injection and demodulation scheme can also be implemented with voltages and currents transposed; i.e., a balanced polyphase signal current is applied, followed by heterodyning of the resulting signal voltages.

\section{Machine Design for Tracking Rotor Saliency}

\section{A. Saturation Effects}

Localized saturation of the rotor slot bridge or opening will induce a spatial modulation in the rotor leakage inductance similar to that intentionally introduced in Fig. 3. The resulting saliency, however, will align with the position of the rotor current vector, and not the rotor position. Likewise, saturation of the main flux path, particularly within the stator, will induce a saliency aligned with the flux vector. Both situations can be shown to add an additional term to the error signal of (16) in the form:

$$
\varepsilon_{f} \approx I_{i 1} \sin \left[2\left(\theta_{r}-\hat{\theta}_{r}\right)\right]+I_{i 2} \sin \left[2\left(\theta_{e}-\hat{\theta}_{r}\right)\right]
$$

where $I_{i 2}$ and $\theta_{e}$ correspond to the magnitude and position of the saturation-induced saliency.

To avoid position estimation errors created by saturation, the effects of the additional term must be attenuated via a compensation or decoupling scheme, or preferably by proper machine design. Simply selecting the minimum slot opening widths to avoid localized saturation under the highest loading can greatly reduce estimation errors.

Note that (17) suggests the intentional tracking of the flux vector (rather than rotor position) in a heavily saturated though 


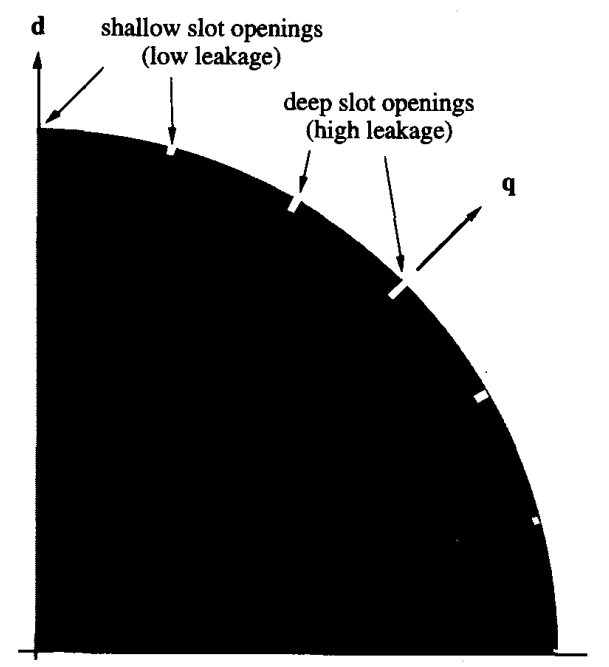

Fig. 6. Rotor of a four-pole induction motor with a modulation in the rotor slot opening depths to create a spatially variant rotor leakage inductance with a nearly uniform magnetizing inductance.

otherwise symmetric induction machine may be possible, thereby enabling torque control at zero and low speeds without position estimation.

\section{B. Modification of Existing Machines}

In machines with normally closed rotor slots, a simple machining process using a slitting saw can be used to open the rotor slots to varying widths. All existing induction motor product lines with closed rotor slots are thus potential candidates for implementation of the proposed estimation scheme.

However, in addition to modulating the leakage inductance, a variation in the slot opening width may also adversely impact the magnetizing inductance, possibly inducing reluctance torque pulsations and/or decreasing the average inductance.

\section{Design of New Machines}

With new machine designs, considerably more flexibility exists for creating a spatial modulation of the rotor leakage inductance. The rotor slot opening depths and fills, and the entire slot shapes, can be varied in addition to the slot openings. The rotor slot leakage can be designed to account for a greater portion of the total leakage in the machine at high frequencies.

Rather than varying the slot opening widths, the depths of the rotor slot openings can be varied as illustrated in Fig. 6 . With this design, the magnetizing inductance remains relatively unaffected. Furthermore, modulation amplitudes considerably higher than by simply varying slot width can be achieved. However, the asymmetry in the rotor lamination may be undesirable from a manufacturing standpoint, especially for large machines that are punched a single slot at a time.

The leakage inductance modulation can also be achieved by varying the fill of the slot opening as shown in Fig. 7. Highfrequency currents and flux are forced to the air gap surface along the $d$-axis, but only to the top of the rotor bars along

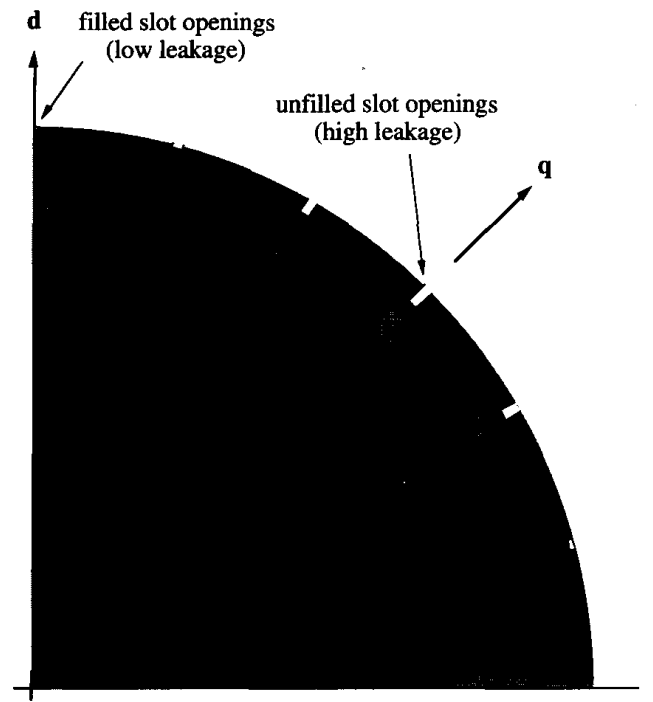

Fig. 7. Rotor of a four-pole induction motor with a modulation in the slot opening fill to create a spatially variant rotor leakage inductance that is seen only at high slip frequencies.

the $q$-axis. Since the available cross section of the slot opening walls is considerably larger for leakage flux along the $q$-axis, the $q$-axis leakage inductance seen at high frequencies will be considerably larger than the $d$-axis inductance, even though the lamination is uniform. The fundamental components will not see a saliency because the rotor currents, which are at low slip frequencies, are uniformly distributed throughout the rotor bar. In this case, the corresponding low-frequency leakage inductance is dictated more by the shape of the lamination, and not the rotor bar or slot fill.

The variation in slot opening fill is easily achieved in large machines with rotor cages fabricated of individual copper bars. In cast cage rotors, spacers can be incorporated within the casting process to restrain the flow of aluminum. Alternatively, for lower volume production, the bars can be cut back in a milling process after casting.

An increase in inverter harmonic losses is one potential drawback of this method of achieving saliency.

\section{EXPERIMENTAL VERIFICATION}

This section demonstrates the viability of creating detectable rotor impedance modulations in existing induction machines, followed by a laboratory implementation of the proposed demodulation scheme.

\section{A. Introduction of Rotor Saliency}

A spatial modulation in the rotor slot leakage inductance was introduced in a conventional three-phase, 5-hp, four-pole induction motor with closed rotor slots. Slot openings were cut using slitting saws on a horizontal milling machine as detailed in the appendix.

Fig. 8 illustrates the resulting spatial modulation in the measured locked-rotor terminal impedance under $60-\mathrm{Hz}$, singlephase, line-line excitation (herein defined to be the stator 


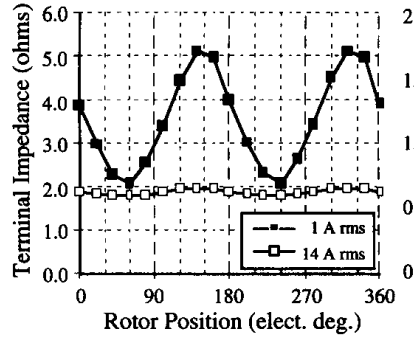

(a)

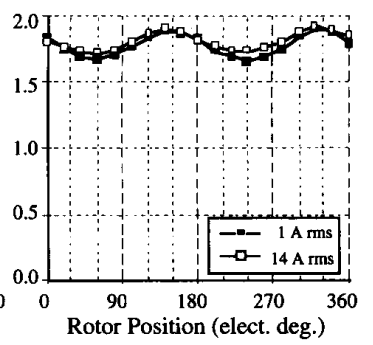

(b)
Fig. 8. Measured $60-\mathrm{Hz}$ locked-rotor terminal impedance magnitudes for machine modifications \#1 (a) and \#2 (b) under light and heavy loading (stator $d$-axis excitation only), illustrating the elimination of rotor slot bridge saturation effects on rotor leakage inductance modulation.

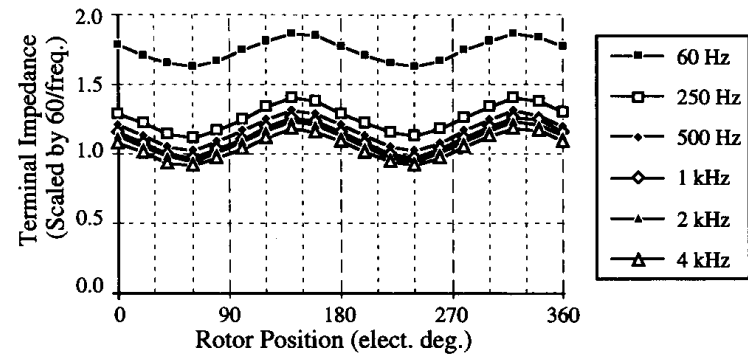

Fig. 9. Measured locked-rotor terminal impedance magnitudes for machine with modification \#2 under variable signal frequency excitation $(\approx 0.7 \mathrm{~A} \mathrm{rms}$, $d$-axis signal excitation).

$d$-axis). Terminal impedance is plotted rather than inductance because the proposed observer actually tracks the impedance modulation, although the rotor slot leakage inductance is the primary modulation source. Even at frequencies as low as 60 $\mathrm{Hz}$, the leakage inductance was found to dominate the terminal impedance.

The combination of closed and open rotor slots (modification \#1 in Appendix) in Fig. 8(a) yields a large rotor position dependent modulation at low-current levels, but as expected, saturation of the rotor slot bridges at higher current levels drastically attenuates the modulation which will lead to significant estimation errors. By opening the remaining closed slots to a width equivalent to that caused by saturation (modification \#2), the impedance modulation is nearly impervious to loading, though attenuated to the saturated level, as shown in Fig. 8(b).

Figs. 9 and 10 illustrate the effect of signal frequency on the measured terminal impedance modulation. As expected from skin effect considerations, the average inductance (scaled impedance) decreases with increasing frequency. However, the modulation amplitude, $\Delta L$ (and $\Delta Z$ ) remains relatively frequency invariant below $\approx 5 \mathrm{kHz}$, beyond which the amplitude rolls off. As a result, the modulation ratio, $\Delta L / L$ (and $\Delta Z / Z$, which corresponds to $I_{i 1} / I_{i 0}$ ) increases with signal frequency until $\approx 1 \mathrm{kHz}$, and then decreases beyond $\approx 5 \mathrm{kHz}$. The trend below $1 \mathrm{kHz}$ is believed attributable to rotor conductor skin effects forcing an increasing proportion of high-frequency flux to the rotor surface, thereby increasing the proportion of total flux experiencing the slot opening modulation. At frequencies above $\approx 5 \mathrm{kHz}$, lamination skin effects are believed to reduce

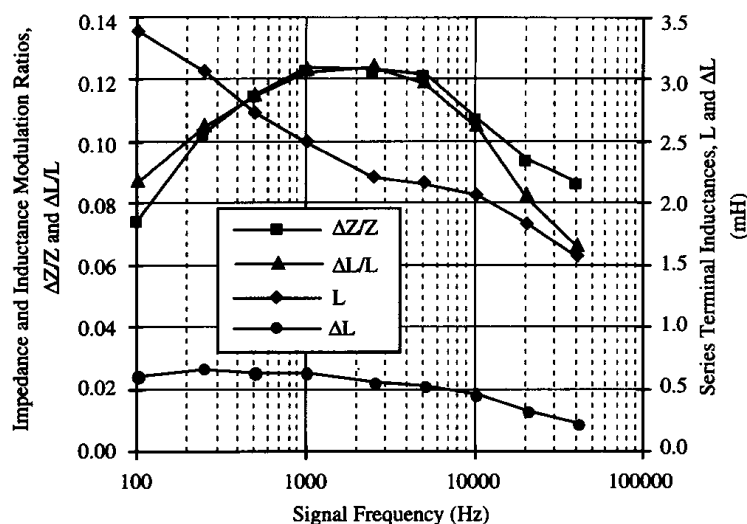

Fig. 10. Measured terminal impedance and inductance modulation amplitudes, $\Delta Z$ and $\Delta L$, relative to spatial averages, $Z$ and $L$, as a function of signal frequency for machine with modification $\# 2$ ( $d$-axis signal excitation $\approx 0.100 \mathrm{~A} \mathrm{rms}$ ).

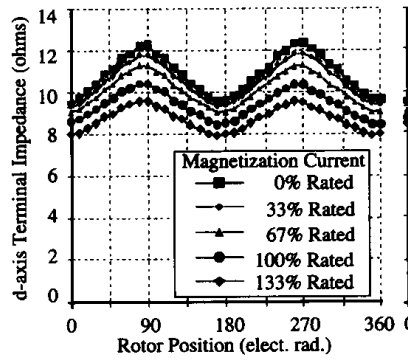

(a)

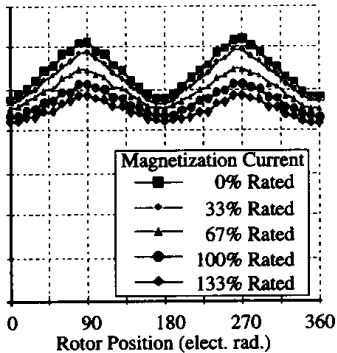

(b)
Fig. 11. Measured terminal impedance along the stator $d$-axis illustrating the effects of operating flux level with flux aligned along the stator $d$-axis (a) and $q$-axis (b). (500-Hz signal, rotor modification $\# 2$ ).

the rotor leakage at a faster rate than the stator leakage, thereby reducing the observed modulation amplitude.

While saturation effects due to current loading were investigated in Fig. 8, the main flux level in the machine was low due to the $60-\mathrm{Hz}$ slip frequency. To investigate the main flux level effects, a dc current of an amplitude corresponding to the magnetizing current was injected first solely into the stator $d$ axis (see Fig. 11(a)) and then into the $q$-axis (see Fig. 11(b)). A $500-\mathrm{Hz}$ low-amplitude $(\approx 0.25 \mathrm{~A}$ rms) signal was used to measure the terminal impedance seen along the stator $d$-axis in both cases. Although the average impedance (inductance) decreased significantly with increasing flux level, the effect on the rotor saliency was relatively small at rated or below-rated flux levels.

\section{B. System Implementation}

A digital implementation of a transducerless indirect field oriented (IFO) system based upon the proposed position and velocity estimation scheme was developed as shown in Fig. 12. The high-frequency signal generation $(500 \mathrm{~Hz})$ and demodulation (including sampling, heterodyning and the Luenberger observer) operated at $16 \mathrm{kHz}$, while the IFO operated at $500 \mathrm{~Hz}$. The PWM VSI switched at $3.4 \mathrm{kHz}$ 


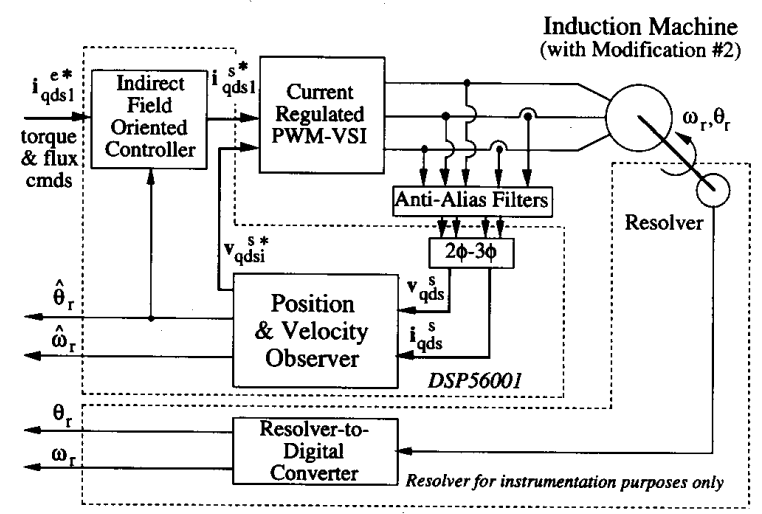

Fig. 12. Implementation of a DSP-based, indirect field oriented, transducerless system.

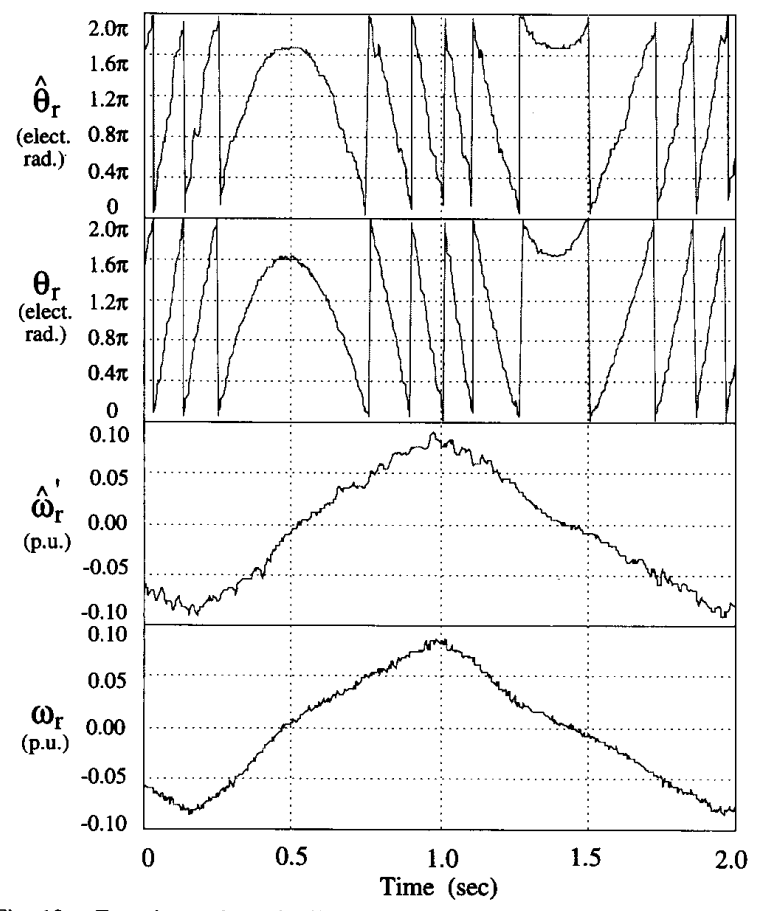

Fig. 13. Experimental results illustrating estimated and measured rotor positions and velocities under low and zero speeds and light loading (33\% flux, $10 \%$ torque).

with a stationary frame PI current regulator with $\approx 10 \mathrm{~Hz}$ bandwidth. The intentionally low bandwidth allowed the $500-\mathrm{Hz}$ signal voltage commands to be directly impressed upon the fundamental current commands without drive circuit modifications at the expense of an operating range limited to zero and low speeds.

Estimated and measured rotor position and velocity under low and zero speed operation and light loading are illustrated in Fig. 13. Some distortion is evident due to deadtime and the low current regulator bandwidth. Inverter deadtime caused undesirable modulations of the applied signal voltages, resulting in similar modulations in the heterodyned error signal.
TABLE I

ROTOR SLOT MODIFICATIONS ON TEST INDUCTION MaChINE

\begin{tabular}{|c|c|c|c|}
\hline Slot Number & \multicolumn{3}{|c|}{ Rotor Slot Opening Width } \\
\hline (11 slots/pole) & $\begin{array}{c}\text { Prior to } \\
\text { Modification }\end{array}$ & $\begin{array}{c}\text { Modification \#1 } \\
\text { mil, (mm) }\end{array}$ & $\begin{array}{c}\text { Modification \#2 } \\
\text { mil, (mm) }\end{array}$ \\
\hline $\begin{array}{c}1-6,12-17, \\
23-28,34-39\end{array}$ & closed & closed & $6(0.15)$ \\
\hline $\begin{array}{c}7-11,18-22, \\
29-33,40-44\end{array}$ & closed & $64(1.6)$ & $64(1.6)$ \\
\hline
\end{tabular}

These modulations directly impacted the estimation accuracy and limited the maximum loading on the machine.

\section{Estimation in Salient aC Machines}

The estimation approach proposed and demonstrated for the induction machine is directly applicable to other types of polyphase ac machines. Machines such as buried and insetmounted permanent magnet synchronous and synchronous reluctance machines are ideal candidates because of their inherent rotor magnetic saliency. For these machines, a modulation in the synchronous reactance as viewed from the stator is tracked rather than the rotor leakage inductance. The signal generation, demodulation, and observer schemes remain the same, however.

\section{CONCLUSIONS}

This paper presented a means of transducerless position and velocity estimation in induction and salient ac machines that has the potential of overcoming the limitations of previous approaches by providing:

1) sustained zero and low speed operation,

2) static and dynamic position and velocity estimation,

3) parameter insensitivity,

4) load independent estimation, and

5) low computation and hardware requirements.

Three key features of the approach are:

1) the utilization of rotor magnetic saliency (introduced as a modulation of the rotor leakage inductance in induction machines),

2) the generation (via the inverter) of a balanced polyphase high-frequency voltage (or current) signal superimposed upon the fundamental, and

3) a closed-loop (observer-based) heterodyning demodulation technique acting upon the resulting signal current (or voltage).

Experimental results verified the viability of the approach. Compensation for inverter deadtime was determined to be necessary for further accuracy improvements.

\section{APPENDIX}

\section{TEST INDUCTION MACHINE}

GE TriClad 5-hp, 230/460v, three-phase, 60-Hz, 1745 r/min, 14.2/7.1 A, Frame 184T, Nema B, 36 stator slots, 44 closed rotor slots. Parameters prior to modification: 


$$
\begin{array}{ll}
r_{s} \approx 0.47 \Omega & L m \approx 49 \mathrm{mH}(\text { at } 230 \mathrm{v}) \\
r_{r} \approx 0.56 \Omega & L_{l s}+L_{l r} \approx 4.5 \mathrm{mH}(\text { at } 14.2 \mathrm{~A}) .
\end{array}
$$

\section{REFERENCES}

[1] H. Nakano and I. Takahashi, "Speed sensorless field oriented control of an induction motor using an instantaneous slip frequency estimation method," in Proc. IEEE PESC Conf. Rec., 1988, pp. 847-854.

[2] D. S. Zinger, T. A. Lipo, and D. W. Novotny, "Using induction motor stator windings to extract speed information," in Proc. IEEE Ind. Applicat. Soc. Annu. Meeting, San Diego, CA, Oct. 1989.

[3] C. Schauder, "Adaptive speed identification for vector control of induction motors without rotational transducers," in Proc. IEEE Ind. Applicat. Soc. Annu. Meeting, 1989, pp. 493-499.

[4] R. M. Cuzner, R. D. Lorenz, and D. W. Novotny, "Application of nonlinear observers for rotor position detection on an induction motor using machine voltages and currents," in Proc. IEEE Ind. Applicat. Soc. Annu. Meeting, Oct. 1990.

[5] L. Ben-Brahim and A. Kawamura, "A fully digitized field-oriented controlled induction motor drive using only current sensors," IEEE Trans. Ind. Electron., vol, 39, no. 3, pp. 241-249, June 1992.

[6] H. Tajima and Y. Hori, "Speed sensorless field orientation control of the induction machine," in Proc. IEEE Ind. Applicat. Soc. Annu. Meeting, 1991, pp. 385-391.

[7] G. Yang and T. H. Chin, "Adaptive speed identification scheme for vector controlled speed sensor-less inverter-induction motor drive," in Proc. IEEE Ind. Applicat. Soc. Annu. Meeting, 1991, pp. 404-408.

[8] H. Kubota, K. Matsuse, and T. Nakano, "DSP-based speed adaptive flux observer of induction motor," in Proc. IEEE Ind. Applicat. Soc. Annu. Meeting, Oct. 1991 , pp. $380-384$

[9] J. F. Brudny, P. Delarue, L. Pruvost, and J. J. Franchaud, "New static speed sensing scheme for induction machine," in SPEEDAM (Symp. Power Electron., Electrical Drives, Advanced Electrical Motors), Positano, Italy, May 1992, pp. 235-240.

[10] G. Henneberger, B. J. Brunsbach, and T. Klepsch, "Sensorless operation of induction machines," in SPEEDAM (Symp. Power Electron., Electrical Drives, Advanced Electrical Motors), Positano, Italy, May 1992, pp. 263-268.

[11] M. Schroedl, "Sensorless control of induction motors at low speed and standstill," in Proc. ICEM'92, pp. 863-867.

[12] Y. R. Kim, S. K. Sul, and M. H. Park, "Speed sensorless vector control of an induction motor using and extended Kalman filter," in Proc. IEEE Ind. Applicat. Soc. Annu. Meeting, Houston, TX, Oct. 1992, pp. 594-599.

[13] P. L. Jansen and R. D. Lorenz, "Accuracy limitations of velocity and flux estimation in direct field oriented induction machines," presented at EPE'93, Brighton, UK, Sept. 1993.

[14] R. D. Lorenz and K. VanPatten, "High resolution velocity estimation for all digital, ac servo drives," in Proc. IEEE Ind. Applicat. Soc. Annu. Meeting, Oct. 1988, pp. 363-368.

[15] D. W. Novotny, D. Maly, S. A. Nasar, and B. Jeftenic, "Frequency dependence of time harmonic losses in induction machines," in Int. Conf. on Electric Machines, Cambridge, MA, Aug. 1990, pp. 233-238.

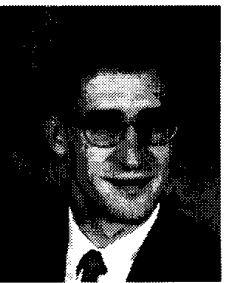

Patrick L. Jansen received the B.S., M.S., and Ph.D. degrees in electrical engineering from the University of Wisconsin, Madison, in 1985, 1987, and 1993, respectively. His research and dissertation focused on the integration of electric machine design with transducerless position and velocity estimation, observer-based direct field oriented ac drives, and linear induction machine design for high-speed material transport systems.

From 1987 to 1989 , he was a development engineer at Machine Dynamics Pty. Ltd., Victoria, Australia, and later an experimental scientist at the Commonwealth Scientific and Industrial Research Organization (CSIRO), Division of Applied Physics, NSW, Australia. He is presently a senior engineer at MK Rail Corporation, Boise, ID, where he is involved in the development of ac propulsion systems for locomotives. He is an Affiliate Assistant Professor at the Department of Electrical Engineering, University of Idaho, Moscow. He has two patents pending.

Dr. Jansen has received two prize paper awards from the IEEE IAS Industrial Drives Committee.

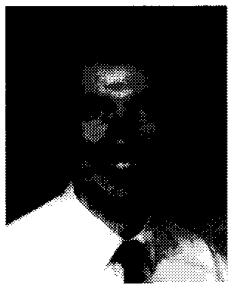

Robert D. Lorenz (S'83-M'84-SM'91) received the B.S., M.S., and Ph.D. from the University of Wisconsin, Madison, in 1969, 1970, and 1984, respectively. From 1969 to 1970 , he did his M.S. the sis research at the Technical University of Aachen, Germany.

Since 1984, he has been a member of the faculty of the University of Wisconsin, Madison, where he is Professor of mechanical, electric and computer engineering. He acts as Associate Director of the Wisconsin Electric Machines and Power Electronics Consortium, and as Co-Director of the Advanced Automation and Robotics Consortium. He was a Visiting Research Professor in the Electrical Drives Group of the Catholic University of Leuven, Belgium, and in the Electrical Drives Institute of the Technical University of Aachen, in the summers of 1989, 1987, and 1991, respectively. From 1972 to 1982, he was a member of the research staff at the Gleason Works, Rochester, NY. His current research interests include sensor integrated electromagnetic actuator technologies, real time digital signal processing and estimation techniques, and ac drive and high-precision machine control technologies. He is an active consultant to many organizations.

Dr. Lorenz is a past Chairman of the IEEE Industry Applications Society Industrial Drives Committee, and is a member of the Industrial Automation and Control Committee, the Electrical Machines Committee, and the Industrial Power Converter Committee. He is a Registered Professional Engineer in the states of New York and Wisconsin. He is a member of ASME, ISA, and SPIE. 